\title{
Dynamic Hysteresis Based Modeling Of Piezoelectric Actuators
}

\author{
Marwan Nafea M., Z. Mohamed*, Auwalu M. Abdullahi, M. R. Ahmad, A. R. Husain \\ Faculty of Electrical Engineering, Universiti Teknologi Malaysia, 81310 UTM Johor Bahru, Johor, Malaysia \\ *Corresponding author: zahar@fke.utm.my
}

\section{Article history}

Received :5 August 2013

Received in revised form :

28 November 2013

Accepted :15 January 2014

\section{Graphical abstract}

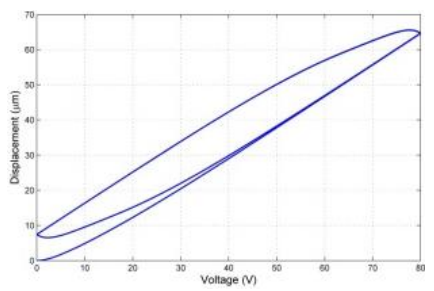

\begin{abstract}
Piezoelectric actuators are popularly applied as actuators in high precision systems due to their smal displacement resolution, fast response and simple construction. However, the hysteresis nonlinear behavior limits the dynamic modeling and tracking control of piezoelectric actuators. This paper studies a dynamic model of a moving stage driven by piezoelectric stack actuator. The Bouc-Wen model is introduced and analyzed to express the nonlinear hysteresis term. Two triangular actuating voltages with frequency of $1 \mathrm{~Hz}$ and amplitudes of $80 \mathrm{~V}$ and $90 \mathrm{~V}$ are applied to drive the piezoelectric stack actuator. The results demonstrate the existence of the hysteresis phenomenon between the input voltage and the output displacement of the piezoelectric stack actuator, and validate the correctness of the model.
\end{abstract}

Keywords: Piezoelectric actuator; hysteresis modeling; Bouc-Wen model

\begin{abstract}
Abstrak
Pemacu piezoelektrik popular digunakan sebagai pemacu sistem berketepatan tinggi memandangkan ia memberikan resolusi sesaran yang kecil, tindak balas yang cepat dan konstruksi yang mudah. Namun, sifat histerisis yang tidak linear menghadkan pemodelan dinamik dan penjejakan bagi pemacu ini. Artikel ini adalah berkaitan penyelidikan model dinamik bagi sistem digerakkan oleh pemacu piezoelektrik berlapis. Model Bouc-Wen diperkenalkan dan dianalisis untuk mendapatkan terma histerisis tidak linear. Dua voltan segitiga dengan frekuensi $1 \mathrm{~Hz}$ dan amplitud $80 \mathrm{~V}$ dan $90 \mathrm{~V}$ digunakan untuk mengerakkan pemacu piezoelektrik berlapis. Keputusan menunjukkan kewujudan fenomena histerisis antara voltan input dan sesaran output bagi pemacu piezoelektrik berlapis, dan mengesahkan kesahihan model.
\end{abstract}

Kata kunci: Pemacu piezoelektrik berlapis; model histerisis; model Bouc-Wen

\subsection{INTRODUCTION}

Piezoelectric actuators are widely used for micro/nano manipulation systems [1], micro-robots [2], vibration active control [3], precision machining [4], and atomic force microscopy [5]. This is due to their special characteristics such as high resolution in nanometer range, fast response, and high stiffness. The major advantage of using piezoelectric actuators is that they do not have any frictional or static characteristics, which usually exist in other types of actuators. However, the main disadvantage of piezoelectric actuators is the nonlinearity, that mainly due to hysteresis behavior, creep phenomenon and high frequency vibration [6].

Hysteresis behavior has a high nonlinear effect on piezoelectric actuators. The nonlinear effect occurs between the applied voltage and output displacement, which causes difficulties in controlling the displacement of the actuator. A well-known description of piezoelectric actuators behavior was published by a standards committee of the IEEE in 1966 and most recently revised in 1987 [7]. This description states that both of the electrical displacement and the material strain exhibited by piezoelectric ceramic are linearly affected by the electrical field and the mechanical stress to which the ceramic is submitted. This linearized description fails to describe the nonlinearities that exist in all piezoelectric ceramics, such as hysteresis, creep and vibration. Furthermore, it fails to describe the dissipative energy behavior of the piezoelectric ceramic. Thus, this description is not accurate enough to be used in recent modeling and control purposes [1].

Therefore, an accurate modeling of hysteresis behavior should be implemented in order to design a controller for hysteresis compensation of the piezoelectric actuators [8]. To study the hysteresis behavior, many hysteresis models have been developed such as the Bouc-Wen model [9], Duhem model [10], Maxwell model [1], Preisach model [11] and Prandtl-Ishlinskii model [12]. From literature, it is found that Bouc-Wen model is widely used to describe the hysteresis behavior of piezoelectric actuators, random vibration analyses and structural engineering, due to its great ability to handle any functional nonlinearity, and system and measurement noise. Furthermore, it is considered as a simple model with few parameters, and it is able to describe a variety of complicated hysteresis loops [13].

This paper studies the dynamic hysteresis modeling of piezoelectric actuators that is based on Bouc-Wen hysteresis model. A moving stage that is driven by a piezoelectric actuator is considered. The effect of the hysteresis behavior on the output displacement is analyzed and studied. 


\subsection{BOUC-WEN HYSTERESIS MODEL}

Bouc hysteretic semi-physical model was proposed initially early in 1971 and then generalized by Wen in 1976 [13]. Since that, it was known as Bouc-Wen model, and has been modified by some authors, such as Baber and Noori [14]. The original Bouc-Wen model and its modified models have been widely used to describe mathematically systems and components with hysteretic behaviors, especially within the areas of mechanical and civil engineering. The model consists of a first-order nonlinear differential equation that relates the input displacement to the output restoring force in a hysteretic way [13]. In piezoelectric actuators, the input is the driving voltage, and the output is the displacement of the actuator.

The function that describes the hysteresis behavior between the force and the displacement was proposed by [15]. Considering Figure 1, where $f$ is force and $x$ is displacement and a function of time, then the value of $f$ at instant time $t$ will depend on the value of $x$ at time $t$ and the past value of $x$. The relationship between the force and displacement can be expressed as:

$\frac{d f}{d t}=g\left(x, f, \operatorname{sign}\left(\frac{d x}{d t}\right)\right) \frac{d x}{d t}$

$\frac{d^{2} x}{d t^{2}}+f(t)=p(t)$

where $g($.$) is a function of x$ and $f, p(t)$ is the input. Equation (1) can be solved by using the variant of the Stieltjes integral $[15,16]$ :

$$
f(t)=\mu^{2} x(t)+\int_{\beta}^{t} F\left(V_{s}^{t}\right) d x(s)
$$

where $\mu$ is the hereditary kernel function that takes into account hysteretic phenomenon, $\beta \in[-\infty,+\infty]$ is the time instant after which displacement and force are defined, $V_{s}^{t}$ is the total variation of $x$ in the time interval $[s, t]$. The function $F$ satisfies the mathematical properties and the hysteresis properties:

$f(u)=\sum_{i=1}^{N} A_{i} e^{-\alpha_{i} u}, \quad$ with $\alpha_{i}>0$

Equations (2)-(4) can then be rewritten as:

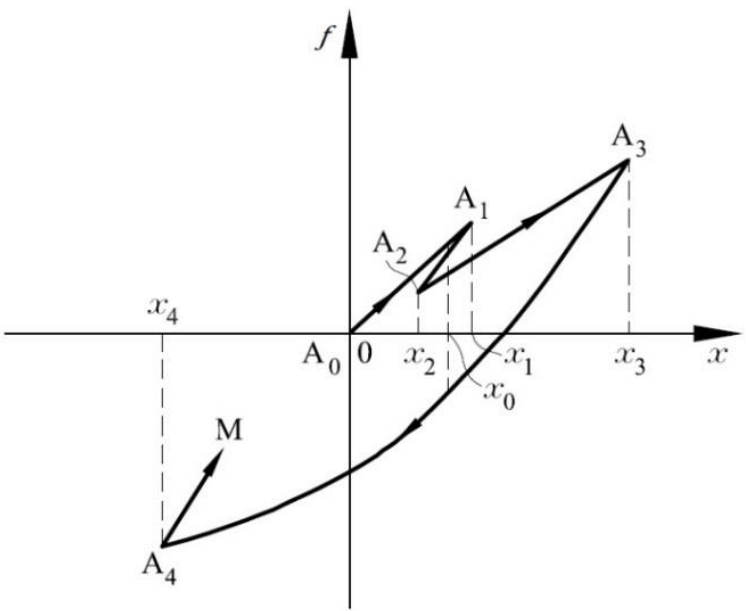

Figure 1 Force versus displacement for a hysteresis function

$$
\frac{d^{2} x}{d t^{2}}+\mu^{2} x+\sum_{i=1}^{N} Z_{i}=p(t) \quad \text { and }
$$

$$
\frac{d Z_{i}}{d t}+\alpha_{i}\left|\frac{d x}{d t}\right| Z_{i}-A_{i} \frac{d x}{d t}=0 ; i=1, \ldots, N
$$

Equation (6) has been extended in [10] to describe the relationship between the restoring force and the hysteresis as:

$\dot{z}=-\alpha|\dot{x}| z^{n}-\beta \dot{x}\left|z^{n}\right|+A \dot{x} \quad$ for $n$ odd

$\dot{z}=-\alpha|\dot{x}| z^{n-1}|z|-\beta \dot{x} z^{n}+A \dot{x} \quad$ for $n$ even

Equations (7)-(8) are the earliest version of Bouc-Wen model, where $\dot{z}$ represents the time derivative of the hysteresis nonlinear term, $0<\alpha<1$ is the post to pre-yielding stiffness ratio that controls the shape of the hysteresis loop, $A$ and $\beta$ are parameters that control the shape and the magnitude of the hysteresis loop, while $n>1$ is a scalar that controls the smoothness of the transition from elastic to plastic response [17].

A physical system with a hysteretic component can be expressed by a map $x(t) \rightarrow \Phi_{s}(x)(t)$, where $x$ represents the time history of the input, and $\Phi_{s}(x)$ is the time history of the hysteretic output variable. Since all mechanical structures are stable in open loop, then for any bounded input $x$, the output of the true hysteresis $\Phi_{s}(x)$ is bounded [13]. Then, the Bouc-Wen model that represents the true hysteresis can be expressed as $[18,19]$ :

$\Phi_{B W}(x)(t)=\alpha k x(t)+(1-\alpha) k z(t)$

$\dot{z}=A \dot{x}-\beta|\dot{x}| z^{n-1} z-\gamma|\dot{x}| z^{n}$

Equations (9) and (10) are known as the generalized model of Bouc-Wen. It should be noticed that some changes were made on the symbols names of the original Bouc-Wen model, $\alpha$ and $\beta$ in the original Bouc-Wen model were replaced by $\beta$ and $\gamma$ respectively in the generalized model of Bouc-Wen. $A, \beta$ and $\gamma$ are parameters that control the shape and the amplitude of the hysteresis loop, $0<\alpha<1$, while $k>0$ is the stiffness factor [20].

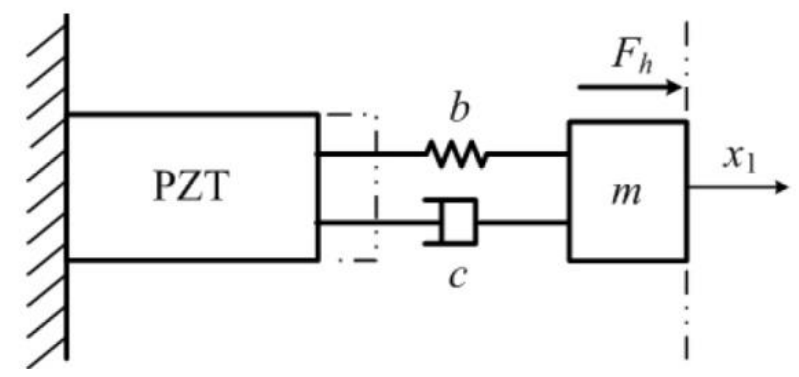

Figure 2 Schematic diagram of a moving stage driven by a piezoelectric actuator [21]

\subsection{SYSTEM MODELING}

The model is a moving stage driven by a piezoelectric actuator. One end is fixed and the other is sliding horizontally. By assuming a high generated force by a piezoelectric actuator comparing to the frictional force, the schematic diagram of the moving stage system is as shown in Figure 2 [21].

In order to make the generalized model of Bouc-Wen suitable for piezoelectric actuator, several assumptions and modifications have been made in Equations (9) and (10). The parameters $A=1$ and $n=1$ are used to remove the redundancy and to achieve smoother hysteresis loop respectively $[22,23]$. Then, the dynamic model of a positioning mechanism based on Bouc-Wen model can be written as $[6$, 24]:

$m \ddot{x}+b \dot{x}+k x=F_{h}=k(d u-z)+F_{\text {ext }}$ 


$$
\dot{z}=\alpha d \dot{u}-\beta|\dot{u}| z-\gamma \dot{u}|z|
$$

where $x$ is the displacement of the stage, $z$ is the hysteresis nonlinear term, and $\dot{x}, \ddot{x}$ and $\dot{z}$ are the derivatives of $x$ and $z$ respectively. $m, b$ and $k$ are the mass, damper coefficient and stiffness factor of the positioning mechanism. $u$ is the applied voltage, $F_{h}$ is the exciting force that generated by the piezoelectric ceramic, while $d$ is the piezoelectric material constant. To solve Equations (11) and (12), the values of the parameters $m, b, k, d, \alpha, \beta$ and $\gamma$ should be identified using estimation and identification methods, such as Genetic algorithms [25], least squares method [26], extended Kalman filter [27].

\subsection{SIMULATION RESULTS}

In this study, for simulation purposes, the values of the parameters of the piezoelectric actuator system have been taken from [6], as given in Table 1. These parameters were identified using a modified quadratic programming with respect to the root-mean-square error. The input voltage is a triangular signal with amplitude of $80 \mathrm{~V}$ and frequency of $1 \mathrm{~Hz}$, as shown in Figure 3 (a), while the response of the system is shown in Figure 3 (b). As indicated by Figure 3 (a) and (b), the output displacement evinces a distortion on both rising and falling slopes, which indicates a nonlinear relationship between the input voltage and the output displacement of the piezoelectric actuator. Based on Bouc-Wen model, the nonlinear relationship between the input and the output is caused by the hysteresis phenomenon that exists in piezoelectric ceramics [28].

The hysteresis phenomenon is demonstrated clearly in Figure 4, which shows the nonlinear relationship between the input voltage and the output displacement of the system. This hysteresis phenomenon is based on the crystalline polarization effect and molecular friction. The displacement generated by piezoelectric actuator depends on the applied electric field and the piezoelectric material constant which is related to the remnant polarization that is affected by the electric field applied to piezoelectric material. The deflection of the hysteresis curve depends on the previous value of the input voltage, which means that piezoelectric materials have memory because they remain magnetized after the external magnetic field is removed. This magnetization makes the output displacement response to the increased input voltage from $0 \mathrm{~V}$ to $80 \mathrm{~V}$ differs from that one to the decreased input voltage from $80 \mathrm{~V}$ to $0 \mathrm{~V}$.

Table 1 Values of the system parameters [6]

\begin{tabular}{cccc}
\hline Parameter & Value & Parameter & Value \\
\hline$m$ & $2.17 \mathrm{~kg}$ & $d$ & $\begin{array}{c}9.013 \times 10^{-7} \\
\mathrm{~m} / \mathrm{V}\end{array}$ \\
$b$ & $4378.67 \mathrm{Ns} / \mathrm{m}$ & $\alpha$ & 0.38 \\
$k$ & $3 \times 10^{5} \mathrm{~N} / \mathrm{m}$ & $\beta$ & 0.0335 \\
$F_{\text {ext }}$ & $0 \mathrm{~N}$ & $\gamma$ & 0.0295 \\
\hline
\end{tabular}
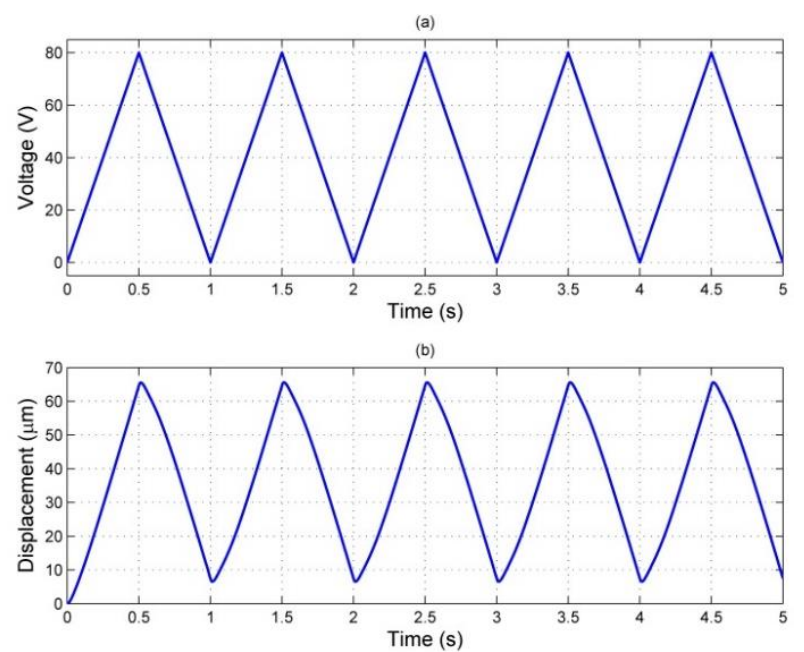

Figure 3 (a) Input voltage with $80 \mathrm{~V}$ and $1 \mathrm{~Hz}$. (b) Output displacement.

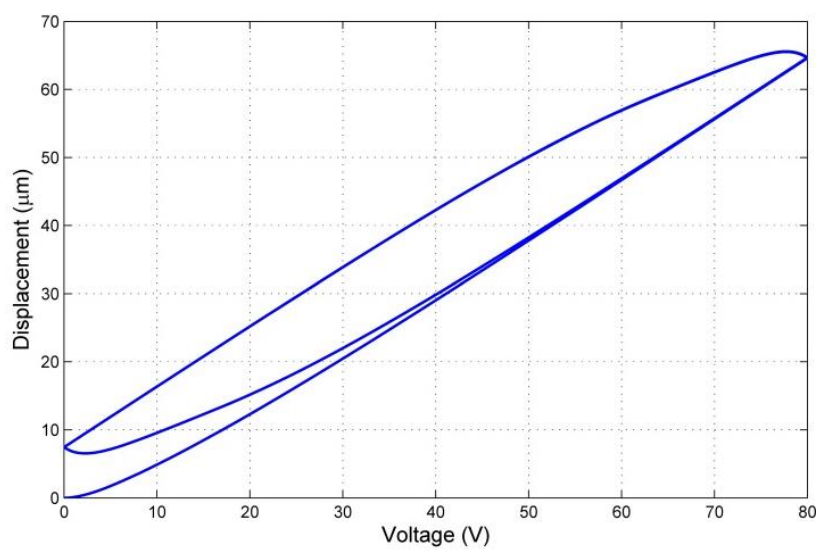

Figure 4 The simulated hysteresis loop with $80 \mathrm{~V}$ and $1 \mathrm{~Hz}$ input frequency.

For further investigation, the input voltage amplitude is increased to $100 \mathrm{~V}$ with the same triangular wave and frequency, as in Figure 5 (a), while the response of the system is shown in Figure 5 (b). From Figure 5 (a) and (b), it can be noticed that output displacement response pursues in a similar manner to that one in Figure 3, as the output displacement still evinces a distortion on both rising and falling slopes. In addition, the maximum output displacement is increased after increasing the input voltage, which indicates a nonlinear proportionality between them, as stated in the dynamic hysteresis model $[1,28]$.

Figure 6 shows the simulated hysteresis curve that relates the input voltage to the output displacement of the system when the input voltage is increased to $100 \mathrm{~V}$. It is clear that the hysteresis curve in Figure 6 takes a similar shape to hysteresis curve in Figure 4. From both figures, it is indicated that the initial ascending curve starts from the origin, but the loops do not go back to the origin even if the applied voltage is back to zero. This is caused by the polarization and elongation that occurs in the piezoelectric material under positive voltages cannot be completely retrieved even if the input voltage returns to zero [28]. 

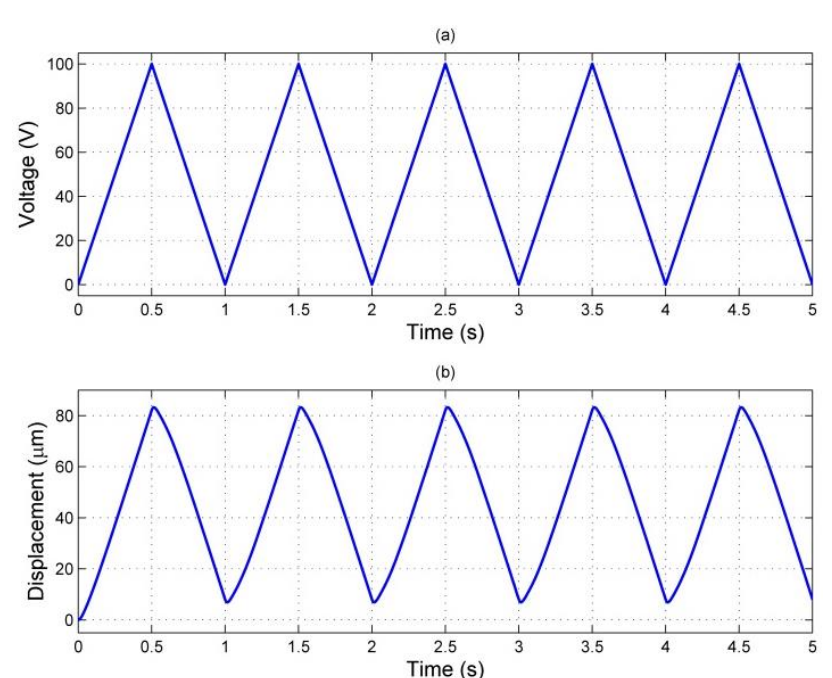

Figure 5 (a) Input voltage with $100 \mathrm{~V}$ and $1 \mathrm{~Hz}$. (b) Output displacement

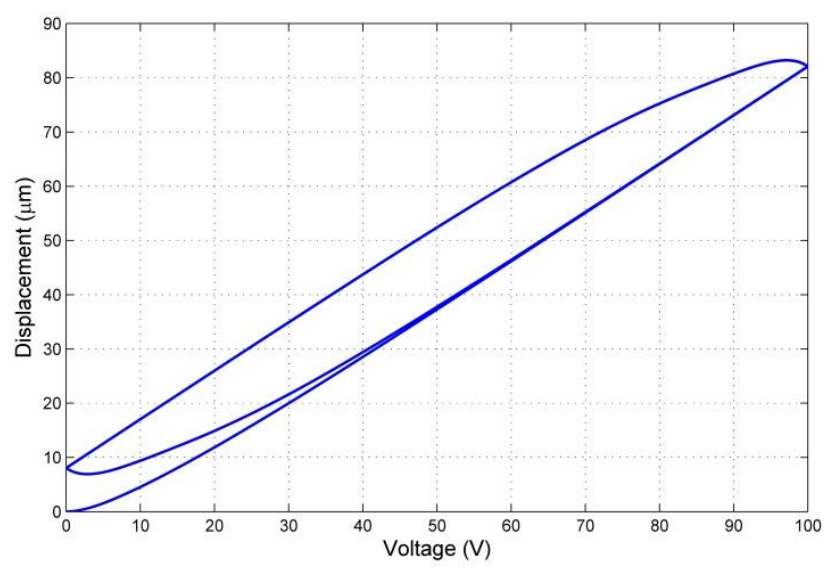

Figure 6 The simulated hysteresis loop with $100 \mathrm{~V}$ and $1 \mathrm{~Hz}$ input frequency
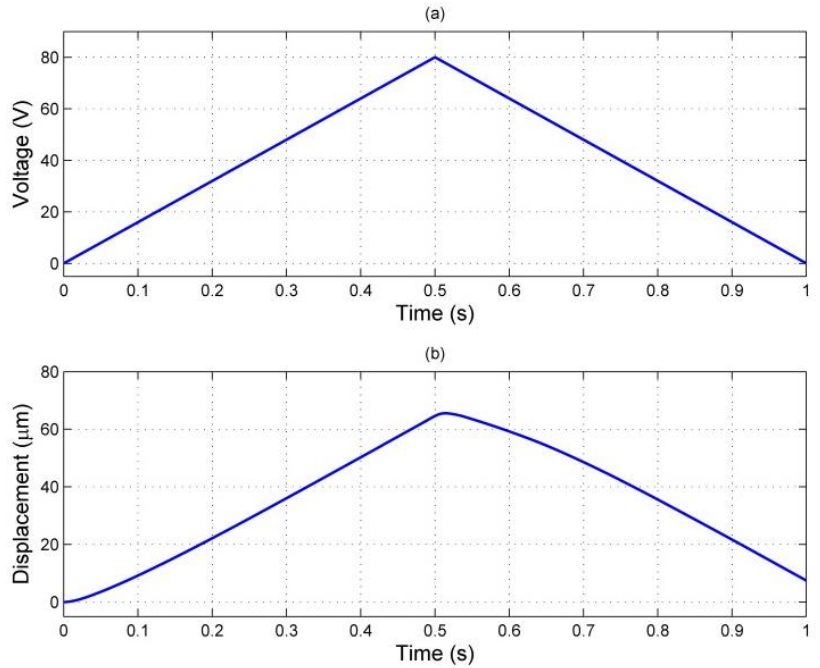

Figure 7 One wave cycle of (a) Input voltage with $80 \mathrm{~V}$ and $1 \mathrm{~Hz}$. (b) Output displacement
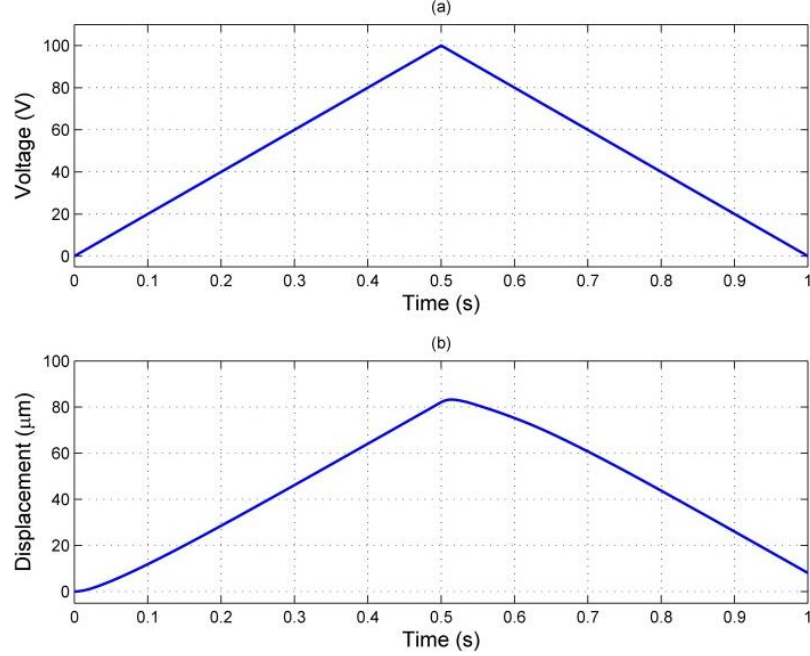

Figure 8 One wave cycle of (a) Input voltage with $100 \mathrm{~V}$ and $1 \mathrm{~Hz}$. (b) Output displacement

Further investigation at one wave cycle of both Figures 3 and 5 demonstrates that the output displacements in both cases exhibit distortions on both rising and falling slopes, and preserve an amplitude-dependent offset, as shown in Figures 7 and Figure 8. Moreover, it is noted that there is a phase lag between the input voltage and the output displacement of the waveforms peaks. Changing the input voltage leads to changing the phase lag between the input and the output. This phase lag indicates the existence of the hysteresis behavior in piezoelectric actuators. In other words, hysteresis can be defined as a phase lag between a periodic input and its corresponding output. These results and observations prove the correctness of the studied model.

\subsection{CONCLUSION}

A dynamic modeling method based on Bouc-Wen hysteresis model is analyzed in this paper. The equivalent dynamic model of the moving stage driven by a piezoelectric stack actuator is derived and simulated. The simulation results prove the correctness of the modeling and the existence of the hysteresis behavior in the piezoelectric stack actuator. It is shown that Bouc-Wen model is suitable to model piezoelectric actuators due to its simplicity with few parameters, and its ability to describe a variety of complicated hysteresis loops.

Further verifications and improvements of the model can be done in the future by using different values of the piezoelectric actuator parameters, and by building and testing the physical system.

\section{References}

[1] Goldfarb, M., \& Celanovic, N. 1997. Modeling Piezoelectric Stack Actuators for Control Of Micromanipulation. Control Systems, IEEE. 17(3): 69-79.

[2] Simu, U., \& Johansson, S. 2002. Evaluation of a Monolithic Piezoelectric Drive Unit for a Miniature Robot. Sensors and Actuators A: Physical. 101(1): 175-184.

[3] Viswamurthy, S. R., \& Ganguli, R. 2007. Modeling and Compensation of Piezoceramic Actuator Hysteresis for Helicopter Vibration Control. Sensors and Actuators A: Physical. 135(2): 801-810.

[4] Caruso, G., Galeani, S., \& Menini, L. 2003. Active Vibration Control of an Elastic Plate Using Multiple Piezoelectric Sensors and Actuators. Simulation Modelling Practice and Theory. 11(5): 403-419.

[5] Croft, D., Shedd, G., \& Devasia, S. 2000. Creep, Hysteresis, and Vibration Compensation for Piezoactuators: Atomic Force Microscopy Application. In American Control Conference, 2000. Proceedings of the 2000 IEEE. 3: 2123-2128).

[6] Sofla, M. S., Rezaei, S. M., Zareinejad, M., \& Saadat, M. 2010. Hysteresis-observer Based Robust Tracking Control of Piezoelectric 
Actuators. In American Control Conference (ACC), 2010 IEEE. 4187-4192.

[7] Standards Committee of the IEEE Ultrasonics, Ferroelectrics, and Frequency Control Society. 1987. An American National Standard: IEEE Standard on Piezoelectricity, The Institute of Electrical and Electronics Engineers, ANSUIEEE Std. New York. 176-1987.

[8] Gu, G., \& Zhu, L. 2010. High-speed Tracking Control of Piezoelectric Actuators Using an Ellipse-based Hysteresis Model. Review of Scientific Instruments. 81(8): 085104-085104.

[9] Wen, Y. K. 1976. Method for Random Vibration of Hysteretic Systems. Journal of the Engineering Mechanics Division. 102(2): 249-263.

[10] Coleman, B. D., \& Hodgdon, M. L. 1986. A Constitutive Relation for Rate-independent Hysteresis in Ferromagnetically Soft Materials. International Journal of Engineering Science. 24(6): 897-919.

[11] Ge, P., \& Jouaneh, M. 1995. Modeling Hysteresis in Piezoceramic Actuators. Precision Engineering. 17(3): 211-221.

[12] Jiang, H., Ji, H., Qiu, J., \& Chen, Y. 2010. A modified prandtlishlinskii Model for Modeling Asymmetric Hysteresis of Piezoelectric Actuators. Ultrasonics, Ferroelectrics and Frequency Control, IEEE Transactions on. 57(5): 1200-1210.

[13] Ismail, M., Ikhouane, F., \& Rodellar, J. 2009. The Hysteresis BoucWen Model, a Survey. Archives of Computational Methods in Engineering. 16(2): 161-188.

[14] Baber, T. T., \& Noori, M. N. 1986. Modeling General Hysteresis Behavior and Random Vibration Application. Journal of Vibration Acoustics Stress and Reliability in Design. 108: 411.

[15] Bouc, R. 1971. Modèle mathématique d'hystérésis. Acustica. 21:1625. (A mathematical model for hysteresis).

[16] Ceravolo, R. Demarie, G. V. \& Erlicher, S. 2007. Instantaneous Identification of Bouc-Wen-Type Hysteretic Systems from Seismic Response Data. Key Engineering Materials. 347: 331-338.

[17] Ikhouane, F., Rodellar, J., \& Hurtado, J. E. 2006. Analytical Characterization of Hysteresis Loops Described by the Bouc-Wen model. Mechanics of Advanced Materials and Structures. 13(6): 463472.

[18] Ikhouane, F., Mañosa, V., \& Rodellar, J. 2007. Dynamic Properties of the Hysteretic Bouc-Wen Model. Systems \& Control Letters. 56(3): 197-205.

[19] Ye, M., \& Wang, X. 2007. Parameter Estimation of the Bouc-Wen Hysteresis Model Using Particle Swarm Optimization. Smart Materials and Structures. 16(6): 2341.

[20] Song, J., \& Der Kiureghian, A. 2006. Generalized Bouc-Wen Model for Highly Asymmetric Hysteresis. Journal of Engineering Mechanics. 132(6): 610-618.

[21] Chang, K. M. 2009. December. Model Reference Adaptive Control For A Precision Positioning System. In Control and Automation, 2009. ICCA 2009. IEEE International Conference on. IEEE. 1086-1091

[22] Ray, T., \& Reinhorn, A. M. 2012. Enhanced Smooth Hysteretic Model with Degrading Properties. Journal of Structural Engineering.

[23] Ikhouane, F., Rodellar, J., \& Rodriguez, A. 2005. May. Analytical Study of the Influence of the Normalized Bouc-Wen Mode Parameters on Hysteresis Loops. In Smart Structures and Materials International Society for Optics and Photonics. 535-542.

[24] Low, T. S., \& Guo, W. 1995. Modeling of a Three-Layer Piezoelectric Bimorph Beam with Hysteresis. Microelectromechanical Systems. Journal of. 4(4): 230-237.

[25] Ha, J. L., Kung, Y. S., Fung, R. F., \& Hsien, S. C. 2006. A Comparison of Fitness Functions for the Identification of a Piezoelectric Hysteretic Actuator Based on the Real-coded Genetic Algorithm. Sensors and Actuators A: Physical. 132(2): 643-650.

[26] Sues, R. H., Mau, S. T., \& Wen, Y. K. 1988. Systems Identification of Degrading Hysteretic Restoring Forces. Journal of Engineering Mechanics. 114(5): 833-846.

[27] Jeen-Shang, L., \& Yigong, Z. 1994. Nonlinear Structural Identification Using Extended Kalman Filter. Computers \& Structures. 52(4): 757 764.

[28] Peng, J. Y., \& Chen, X. B. 2012. Novel Models for One-sided Hysteresis of Piezoelectric Actuators. Mechatronics. 22(6): 757-765. 